\title{
TRABALHO DE CAMPO NA GEOGRAFIA: CONSTRUINDO POSSIBILIDADES DE ENSINO E APRENDIZAGEM SOBRE O RIO GRANDE DO SUL
}

\author{
Daniel Cristianetti Tessaro ${ }^{(a)}$ \\ (a) Instituto de Ciências Exatas e Geociências, Universidade de Passo Fundo. E-mail: daniel_tessaro@hotmail.com
}

\author{
EIXO: GEOGRAFIA FÍSICA - CURRÍCULO, FORMAÇÃO E PRÁTICAS DE ENSINO
}

\begin{abstract}
Resumo
Dentre as várias maneiras de se transmitir conhecimento geográfico, considera-se o trabalho de campo uma atividade metodológica indispensável no sentido de compreender e entender o espaço, favorecendo, assim, uma ligação entre a teoria e a prática. Consequentemente, esta pesquisa consiste em formar uma análise crítica e minuciosa da importância do trabalho de campo e a forma de como ele vem sendo executado no ensino da Geografia, nos cursos de licenciatura e na educação básica (Ensino Fundamental e Ensino Médio). A metodologia apresentada no decorrer, centra-se em um relato de trabalho de campo realizado em vários ambientes do Estado do Rio Grande do Sul, desenvolvido por intermédio da Universidade de Passo Fundo, em conjunto com alunos e professores do II e IV Nível de Geografia Licenciatura.
\end{abstract}

Palavras chave: : Educação no contexto atual. Ensino da Geografia. Trabalho de campo.

\section{Introdução}

Após a realização de inúmeras pesquisas de campo, durante o decorrer do curso de Geografia, em diferentes momentos, no qual esta pesquisa conclui-se, percebe-se a importância de investigações em campo para a formação do professor de Geografia e, consequentemente, as possíveis contribuições para o aluno da educação básica, no momento em que nos encontramos diante de um dilema de grandes obstáculos impostos pelo sistema educacional brasileiro.

Em vista disso, faz-se necessário o trabalho de campo no ensino da Geografia, a fim de estudar a espacialização das ocorrências humanas, que abrangem o uso dos recursos naturais e os aspectos econômicos, políticos e sociais de um determinado lugar, objetivando, assim, uma compreensão mais esmiuçada dos diferentes aspectos que cercam uma determinada realidade.

Nada obstante, atualmente, as aulas de Geografia, no cenário escolar, são realizadas, de certa maneira, distante do objeto de estudo, colocando em risco a construção do conhecimento do alunado. Todavia, os educadores precisam tornar o ensino mais atrativo, relacionando as curiosidades dos alunos com conhecimentos geográficos, a fim de reformar as condições do saber. 
As mudanças atentam para um ensino educacional inovador, que consiga promover a percepção e a assimilação dos fatos explanados. Nesse segmento, mostra-se conveniente utilizar metodologias diferenciadas (ou não), que apresentem estratégias singulares, onde se possa desenvolver a curiosidade dos alunos instigando-os pela busca de um conhecimento novo; isto é, no que se refere ao ensino da Geografia, um conhecimento prazeroso que possa ser explorado a cerca de recursos e metodologias acessíveis, disponíveis em nosso meio, como por exemplo: através de imagens de satélites, folders que divulgam o turismo, SIGs gratuitos, softwares, jornais, Google Earth, maquetes, perfis topográficos, Whatssap, fotos, guias telefônicos e propagandas de imóveis que sempre trazem mapas, croquis, fotos e desenhos e, por último, mas não menos importante, os trabalhos de campo.

Dessa maneira, o docente manifesta-se de substancial relevância na forma de conduzir e explanar essas metodologias. É necessário que os conteúdos não sejam espontaneamente transferidos aos aprendizes; ou seja, não adianta de nada usar diferentes recursos, sair a campo e não ser capaz de construir um conhecimento novo no alunado. Pelo contrário, o orientador precisa desenvolver possibilidades de raciocínio espacial como um todo, transformando os discentes em sujeitos reais da construção do saber, adjunto ao seu educador.

Para tanto, o presente estudo focará em mostrar aos leitores a importância do trabalho de campo, refletindo, ainda assim, sobre as possíveis contribuições que seu emprego proporciona no processo de ensino aprendizagem, instigando o aprendiz a um olhar mais crítico da realidade que o cerca. Além disso, abordará o papel do ensino da Geografia e a interdisciplinaridade, diante de uma sociedade com profundas desigualdades sociais e de extremo autoritarismo das escolas.

O tema de estudo foi baseado no trabalho de campo desenvolvido por intermédio da Universidade de Passo Fundo, em conjunto com alunos e professores do II e IV nível de Geografia Licenciatura.

Os processos metodológicos utilizados para a elaboração do conteúdo teórico deste trabalho respaldam-se em uma pesquisa bibliográfica plausível, de temáticas primordiais capazes de sustentar a indagação. Temáticas estas encontradas em dissertações, teses, revistas da área, livros de autores letrados e por fim, mas não menos importante, em trabalhos completos divulgados pela Associação dos geógrafos Brasileiros - AGB.

\section{Referencial teórico}

A composição teórica deste artigo foi elaborada a partir do uso de autores que apresentam viés a cerca dos fundamentos metodológicos do ensino e aprendizagem de Geografia na educação básica brasileira. Para 
aludir mais especificamente o tema, circunscreveu-se, através de escritores renomados diante do modelo de ensino/aprendizagem por meio de metodologias alternativas de ensino, como por exemplo, o trabalho de campo. Para tanto, ao falar de trabalho in loco é essencial, adjunto, debater o contexto escolar, colocar em discussão ideias e elementos que envolvam o espaço geográfico escolar das crianças e adolescentes.

Assim, num primeiro momento, será contextualizado a educação no cenário atual e o papel do ensino da Geografia numa sociedade caracterizada, sobretudo, pelas grandes diferenças sociais e pelo absolutismo das escolas. Logo em seguida, uma análise crítica da importância do trabalho de campo no ensinamento geográfico e, por fim, um relato de experiência de campo realizado em vários ambientes do Estado do Rio Grande do Sul.

Para assuntos que abrangem a educação em perspectiva, foram utilizados letrados de bastante destaque no cenário educacional brasileiro, entre eles: Gadotti (2000), Pontuschka (2002), Castrogiovanni (2001; 2014), Santos (1994) e Freire (2013).

Oliveira (2008), Kaercher (2002), Cavalcanti (2002), Callai (1998), por exemplo, além de enfatizar vários aspectos da prática educativa ligada à Geografia, a contar de uma concepção teórico-metodológica de ensino, abordam as adaptações necessárias na direção de proporcionar situações de aprendizagem que valorizem os princípios dos alunos.

Lacoste (1976; 1985) é importante para a discussão do ensino em perspectiva e o modo que se faz Geografia nas salas de aula, indicando um novo real significado da ciência. Atrelado a isso, o autor faz um contraponto essencial de como as atividades em campo estão sendo empregadas no ensino da Geografia.

Para questões que envolvem os processos de elaboração de trabalho de campo e também seu surgimento, Neves (2010) e Fantinel (2000) demonstram claramente a importância das investigações dos fenômenos de certo lugar. Outro ponto importante apresentado pelos autores consiste na participação ativa dos alunos no processo de elaboração dessa prática.

Ross (2005) foi citado, pois descreve as diversas representações geomorfológicas do Rio Grande do Sul.

\section{A educação no contexto atual e o ensino de Geografia}

As grandes transformações ocorridas em nossa sociedade com o passar das décadas, entre elas o surgimento e o aperfeiçoamento de novas tecnologias e a velocidade com que recebemos as informações, de uma maneira geral, vêm proporcionando (ou não) um upgrade também no cenário escolar, fato que força os profissionais de educação a uma nova visão de ensino-aprendizagem. 
Para ter eficácia, o processo de aprendizagem deve, em primeiro lugar, partir da consciência da época em que vivemos. Isto significa saber o que o mundo é e como ele se define e funciona, de modo a reconhecer o lugar de cada país no conjunto do planeta e o de cada pessoa no conjunto da sociedade humana. É desse modo que se podem formar cidadãos conscientes, capazes de atuar no presente e de ajudar a construir o futuro (SANTOS, 1994, p. 121).

De acordo com Gadotti (2000), a educação da nova era apresenta-se sob duas formas distintas: de um lado, tem-se um sistema escolar governamental que não consegue oferecer uma educação básica de qualidade, de outro as novas matrizes teóricas que não apresentam consistência global para apontar uma direção realmente segura em uma época de inúmeras e céleres transformações sócio-espaciais.

Nesse sentido, muitas escolas contemporâneas não conseguem acompanhar essas transformações. De forma a complementar essa discussão é importante citar Castrogiovanni (2014, p.12), em que comenta:

A escola não se manifesta atraente frente ao mundo contemporâneo, pois não dá conta de explicar e textualizar as novas leituras de vida. A vida fora da escola é cheia de mistérios, emoções, desejos e fantasias, como tendem a ser as ciências. A escola parece ser homogênea, transparente e sem brilho no que se refere a tais características. É urgente teorizar a vida, para que o aluno possa compreendê-la e representá-la melhor e, portanto, viver em busca de seus interesses.

Assim sendo, a prática pedagógica e a condução do processo de ensino-aprendizagem proposta pelos agentes educacionais da atualidade precisam ser transformadas profundamente, para que a escola deixe de ser vista pelo aluno como uma mera obrigação a ser cumprida e passe a ser gestora de um profundo conhecimento, capaz de formar/transformar seres atuantes em uma sociedade caracterizada pelas profundas desigualdades sociais.

Na mesma linha de pensamento, Pontuschka (2002) afirma que os alunos, na grande maioria os adultos, apresentam uma concepção de escola bastante tradicional. Esse ponto de vista precisa ser rompido com a contribuição do professor, através da ampliação da cultura desse aluno, para que ele consiga compreender a importância de sua existência, no sentido individual e nos papéis que exerce no meio social em que vive.

De acordo com esse contexto, pode-se afirmar que a escola não deve ser lugar de transferência de informação, mas sim da construção do conhecimento, devendo o docente "saber que ensinar não é transferir conhecimento, mas criar as possibilidades para a sua própria produção ou sua construção" (FREIRE, 2013, p.47, grifo do autor). Contudo, essa criação/produção, deve ser estruturada mediante a prática e a teoria. "Não posso falar bonito sobre as razões ontológicas, epistemológicas e políticas da 
Teoria. O meu discurso sobre a Teoria deve ser o exemplo concreto, prático, da teoria" (FREIRE, 2013, p. 47).

Na mesma linha de pensamento, no que se refere ao ensino da Geografia, busca-se aqui, discutir sobre a dificuldade do avanço da Geografia Crítica nas escolas de Ensino Fundamental e Médio. Para Kaercher (2002, p. 222), a Geografia continua a apresentar um ensino convencional, que produz verdades cristalizadas, mantendo-a como algo chato e longe do dia a dia dos alunos. Segundo ele, o ensino da Geografia esta desacreditado, apresenta uma visão cristalizada e monótona da ciência que só sabe descrever a natureza e fornecer informações gerais de lugares e assuntos. Prossegue no assunto, apresentado possíveis soluções e indicando uma significativa mudança metodológica, que seja capaz de alterar a relação do professor/aluno, exercendo uma postura renovada, de maior diálogo, mas não apenas das partes, como também, do próprio conhecimento.

É relevante aqui, mesmo que brevemente, apresentar e discutir sobre os objetivos do ensino de Geografia em sala de aula. Para Callai (1998, p.57), existem três razões para aprender Geografia. Primeiramente, para conhecer o mundo e obter informações dele. Segundamente, para estudar, analisar e tentar explicar (conhecer) o espaço alterado pelo homem. E, por último, mas não menos importante, enquanto matéria de ensino, permitir que o aluno se perceba como participante do espaço em que vive, onde os fenômenos que ali acontecem "são resultados da vida e do trabalho dos homens e estão inseridos num processo de desenvolvimento" (CALLAI, 1998. p, 57).

Na mesma linha de pensamento, segundo Cavalcanti (2002, p. 12), o estudo geográfico "consiste em levar as pessoas em geral, os cidadãos, a uma consciência da espacialidade das coisas, dos fenômenos que elas vivenciam, diretamente ou não, como parte da história social”. Assim sendo, um estudo de espacialidade necessita de um diagnóstico da sociedade e da natureza, bem como do processo decorrente da relação entre as duas.

Segundo os Parâmetros Curriculares Nacionais, a finalidade da Geografia no Ensino Fundamental é "alfabetizar o aluno espacialmente em suas diversas escalas e configurações, dando-lhe suficiente capacitação para manipular noções de paisagem, espaço, natureza, Estado e sociedade" (PCN, Ensino Médio, p. 30). Já, para o Ensino Médio, os Parâmetros indicam que "o aluno deve construir competências que permitam a análise do real, revelando as causas e efeitos, a intensidade, a heterogeneidade e o contexto espacial dos fenômenos que configuram cada sociedade" (PCN, Ensino Médio, p. 30).

A fim de contestar essa incompatibilidade com a realidade apresentada no PCN, a Geografia da atualidade não está conseguindo transmitir de forma integral a demanda que os documentos norteadores da educação brasileira exigem. "Todos sabemos, o ensino de uma forma geral e especificamente o de geografia passa 
por profunda crise. $\mathrm{O}$ saber ensinado está longe de permitir aos jovens sequer entender o mundo, quanto mais transformá-lo" (OLIVEIRA, 2008).

O geógrafo Yves Lacoste, no ano de 1976, lançou sua principal obra - A Geografia: Isso serve, em primeiro lugar, para fazer a guerra. Sendo a mais forte crítica da Geografia Tradicional. O autor critica a maneira de se fazer Geografia nas salas de aula, indicando um novo real significado da ciência.

Lacoste (1997, p. 21) alerta que o conhecimento geográfico apresenta-se obsoleto, isto é, uma disciplina maçante e simplória, onde os alunos não aguentavam mais ouvir falar das aulas que enumeravam o relevo, o clima, a vegetação e a população de cada país. Logo, a televisão, os jornais, as revistas e o cinema da atualidade, encarregam-se em representar de uma maneira bem mais simples e objetiva essas características.

Decorrido mais de 40 anos até os dias de hoje, infelizmente as denúncias intituladas por Lacoste continuam servindo de referência para muitos pesquisadores e professores de Geografia. Lamentavelmente por quê? Porque "o invisível quando não tem sentido deixa de existir. A riqueza do espaço temporal, tratado pela geografia, desaparece na globalização" (CASTROGIOVANNI, 2001 p. 83).

\subsection{O uso do trabalho de campo no Ensino da Geografia}

Retornando aos objetivos da ciência geográfica, mais precisamente, no que se refere nas investigações dos fenômenos de certo lugar, o trabalho de campo está ligado ao próprio surgimento da Ciência Geográfica, sendo necessariamente empregado por "Alexandre Von Humbolt, considerado um dos pais da Geografia, em suas viagens ao redor do mundo (...) buscava compreender a dinâmica do espaço geográfico explorado através da descrição, análise, comparação e interpretação dos fenômenos” (NEVES, 2010, p. 15).

Nos tempos que correm, o trabalho de campo no ensino da Geografia é uma prática não muito usual, tanto nos cursos de graduação quanto no Ensino Médio e Fundamental. Ocasionalmente acontecem durante o ano, ou em muitos casos, nem acorrem.

Em síntese, Lacoste (1985) afirma que atividade in loco tem importância fundamental na formação dos estudantes de Geografia, mas insatisfatória, pois, da maneira que é realizada, não passa de uma iniciação à pesquisa a uma excursão turística, visto que quando "os professores, nas diferentes paradas que previram no percurso, fazem um discurso diante dos estudantes passivos" (LACOSTE, 1985. p, 13).

E se estas "excursões" fossem previamente problematizadas, realizando indagações a cerca do que será observado? Certamente contribuiriam significativamente para o processo de aprendizagem dos envolvidos. 
Lacoste acredita ainda que os alunos, antes de concluir a graduação, precisariam passar por longos e contínuos campos. Em outras palavras, seriam marcados por caminhadas e convívio com a realidade local, seja nas proximidades da universidade, na casa, na escola ou no próprio bairro.

Sob igual perspectiva, as atividades externas ao educandário, muitas vezes são organizadas e planejadas sem a devida participação dos alunos. Isto é, não há atuação do aprendiz na organização do roteiro e muito menos na escolha dos fenômenos a serem analisados. Os professores escolhem as localidades, as paradas, os horários e os dias/horas de duração da atividade.

Nesta linha de pensamento, Neves (2010. p, 18) observa que "dificilmente os professores do ensino superior envolvem os alunos no processo de elaboração dos trabalhos de campo dos quais eles participam", obstaculizando uma pesquisa individual e findando valer-se apenas de pesquisas já realizadas.

Por este ângulo, quando o aluno se limita a ouvir o professor e, consequentemente, memorizar a fala, o campo servirá apenas de padrão do que já foi evidenciado na escola. Todavia, se o ensino é voltado no aprendiz, "a ênfase do campo volta-se para os processos de aquisição do conhecimento pelo aluno; a metodologia fundamenta-se no estágio cognitivo, interesse e ritmo de aprendizado do aluno, e não em mecanismos de transmissão do saber pelo professor aos alunos" (FANTINEL, 2000, p.11). Assim, o aluno participa ativamente do processo, deixa de ser mero receptor de informações e passa a construir seu próprio conhecimento.

Para a efetivação de uma prática mais eficiente, é aconselhável colocar os alunos em situação de trabalho já no pré-campo, na hora do planejamento e organização, tornando como ponto inicial o conhecimento prévio daquilo que será analisado posteriormente.

Durante o campo, os professores necessitam apresentar indagações aos alunos, discutindo e fazendo apontamentos que agucem o interesse, de tal forma que eles percebam a importância e a necessidade dessa atividade para a formação pessoal, estimulando-os a se tornarem ativos durante todo o processo.

Posteriormente à atividade, as aulas pós-campo precisam ser destinadas à revisão de tudo que foi observado in loco. A avaliação deve ser realizada em parceria com alunos professores, e quem sabe com a comunidade. Os materiais recolhidos precisam ser colocados em defrontação.

\section{Relato de experiências}

A partir de agora este estudo centra-se em gerar um relato de trabalho de campo, realizado em vários ambientes do Estado do Rio Grande do Sul, durante três dias. Cabe aqui ressaltar que a tarefa foi bem 
sucedida, porém não é receita para ninguém. Tange ao professor entender e analisar qual a melhor metodologia para cada turma na elaboração e realização de uma atividade dessa magnitude.

O trabalho foi desenvolvido por intermédio da Universidade de Passo Fundo, em conjunto com alunos e professores do II e IV nível de Geografia Licenciatura. A tarefa apresentou um grande aproveitamento em ambos os níveis de ensino.

A ação explorou os quatro compartimentos geomorfológicos presentes no Estado do Rio Grande do Sul, sendo eles: Planaltos e Chapadas da Bacia do Paraná, Depressão Periférica Sul-Rio-Grandense, Planalto Sul-Rio-Grandense e Planícies e tabuleiros litorâneos (ROSS, 2005). Para isso, foram percorridos aproximadamente 1700 quilômetros, num total de trinta e três municípios gaúchos.

A iniciativa desta atividade deu-se por mediação dos alunos do IV nível, que passaram a convidar a turma do nível II para acompanhamento. A primeira preocupação foi definir, juntamente com todos os estudantes (II e IV nível) e professores do curso, os objetivos e as etapas do trabalho, onde fosse possível um melhor entendimento dos diversos temas teóricos discutidos em sala de aula.

Definiu-se o roteiro, a partir da proposta inicial dos professores, o qual se realizou em três dias, saindo do município de Passo Fundo, movendo-se por Carazinho, Colorado, Saldanha Marinho, Santa Bárbara do Sul, Ibiruba, Cruz Alta, Tupanciretã, Julio de Castilhos, Itaara, Santa Maria, São Sepé, Caçapava do Sul, Santana da Boa Vista, Piratini, Canguçu, Pelotas, Rio Grande, Santa Vitória do Pamar, Chui (brasileiro)/Chuy (uruguaio), voltando por Santa Vitória do Palmar, Rio Grande, Pelotas e Canguçu. Posteriormente, seguindo em direção a Encruzilhada do Sul, Pantano Grande, Rio Pardo, Santa Cruz do Sul, Sinimbu, Herveiras, Gramado Xavier, Barros Cassal, Soledade, Tio Hugo, Ernestina, até chegar ao ponto de partida.

A turma mais avançada foi organizada em seis grupos, e cada grupo se responsabilizou por executar apresentações durante as paradas. Os indivíduos de cada equipe ficavam encarregados de localizar os demais geograficamente, explanar sobre a história do município ou da região, abordar questões relacionadas ao clima, geologia, geomorfologia, hidrografia, população, economia e biogeografia daquele local. Além disso, pontualmente falar sobre temas específicos pré-definidos, como por exemplo: a transição entre a Depressão e o Escudo Cristalino; a importância econômica das áreas de mineração; impactos ambientais; parques eólicos; fronteira Uruguai/Brasil; depósitos coluviais; hidrografia; solo; estação ecológica do Taim.

Essa atividade foi muito bem concedida pelos acadêmicos que confirmaram a importância e a necessidade de suas participações ativas no trabalho de campo, servindo de instrumento pedagógico para a formação 


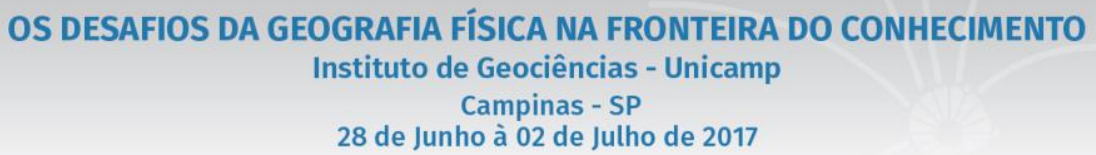

de professores de Geografia, bem com para prática preceptoral. Por fim, os grupos concluíram in loco suas pesquisas e todos os indivíduos, pós-campo, precisariam elaborar um artigo científico, no qual esta pesquisa incide-se.

Durante todo o percurso, mais precisamente após as apresentações das equipes, os professores acompanhantes realizaram, dentro do ônibus, várias explicações, formalizando apontamentos e indagações locais, que por sua vez despertou a curiosidade dos alunos.

\section{Considerações finais}

Há necessidade de um novo ensino, com novas formas de pensar e agir com a finalidade de construir no aluno um profundo conhecimento, o qual se torne capaz de formar/transformá-los em seres atuantes em uma sociedade caracterizada pelo extremo autoritarismo das escolas e por imensas desigualdades sociais. Escolas estas, contemporâneas e tradicionais que não conseguem explicar e textualizar as novas transformações globais.

Nesse sentido, a escola tem-se mostrado um ambiente que desbrava pouco, ou nada, os saberes extraescolares, separando o conhecimento científico da realidade cotidiana dos aprendizes. O que resulta em tédio e desinteresse dos que passam pela Educação Básica de Ensino. Basta olhar as estatísticas nacionais de evasão escolar para se deparar com a triste realidade, um em cada quatro alunos que inicia o Ensino Fundamental abandona os estudos antes de completar a última série do Ensino Médio.

Nessa perspectiva, entende-se que não se aprende a caminhar com aulas teóricas de equilíbrio e/ou de postura ereta. Aprende-se "errando", caindo, tentando várias vezes, levantando-se, até que se consiga caminhar de forma consistente. Logo, a escola precisa ser generosa, oferecer sustentação aos eventuais "enganos". As falhas são fundamentais para os alunos aprenderem a caminhar, a falar, a escrever e, porque não, para descobrir a Geografia que se faz presente em nosso meio?

A construção do saber geográfico, a maioria das vezes, é condensado na fala do professor frente a alunos passivos. A Geografia transmitida em sala de aula está longe do ideal. Diante disso, o professor necessita, não apenas transferir conteúdos, mas sim apresentar uma concepção de conhecimento da nossa ciência, além de buscar novas metodologias de ensino, no sentido de, francamente, cativar os alunos durante as aulas.

Assim, entende-se que a atividade em campo precisa ser enfatizada na sua importância e relevância como instrumento primordial para o ensino e aprendizagem. Todavia, as barreiras da sala de 
aula precisam ser rompidas, quem sabe, através dessa dinâmica o ensino de Geografia colaborará para que o aluno teorize a vida, entendendo-a e revelando-a geograficamente.

Em contrapartida, com o intuito de um melhor aproveitamento dessas atividades, indica-se uma participação mais ativa do alunado, desde o início do processo, no momento do planejamento e organização das atividades, até as etapas finais.

Em relação à aplicação do trabalho de campo, o qual se desenvolveu por intermédio da Universidade de Passo Fundo em conjunto com alunos e professores do II e IV nível de Geografia Licenciatura, adéqua-se complementar ainda que a tarefa foi bem sucedida. Porém que fique claro, o que aqui foi descrito são apenas exemplos e não receitas exatas. Cabe aos educadores analisarem qual a melhor metodologia para cada turma na elaboração e realização de uma ação dessa importância.

\section{REFERÊNCIAS}

BRASIL. Ministério da Educação. Parâmetros curriculares nacionais (Ensino Médio). Brasília: MEC/SEF, 1997.

CALLAI, H. C. O ensino de geografia: recortes espaciais para análise. In: CASTROGIOVANNI et al. (Org.) Geografia em sala de aula: práticas e reflexões. Porto Alegre: Associação dos Geógrafos Brasileiros, Seção Porto Alegre, 1998.

CASTROGIOVANNI, A. C. E agora, como fica o ensino da Geografia com a globalização? In: CASTROGIOVANNI et. al. (Org.). Geografia em sala de aula: práticas e reflexões. 3. ed. Porto Alegre: Ed. da UFRGS, 2001.

CAVALCANTI, L. S. Geografia e práticas de ensino. Goiânia: Alternativa, 2002.

FANTINEL, L. M. Práticas de campo em fundamentos de geologia introdutória: papel das atividades de campo no ensino de fundamentos de geologia no curso de geografia. Campinas: Inst. Geociências. UNICAMP. 2000. (Dissert. mestrado em Educação Aplic. Geociências).

FREIRE, P. Pedagogia da autonomia - saberes necessários à prática educativa. 47. ed. Rio de Janeiro: Paz e Terra, 2013.

GADOTTI, M. Perspectivas atuais da educação. Porto Alegre: ed. Artes Médicas, 2000.

KAERCHER, N. A. O gato comeu a geografia crítica? Alguns obstáculos a superar no ensinoaprendizagem de geografia. In: PONTUSCHKA, N. N. e OLIVEIRA, A.U. (Org.). Geografia em Perspectiva: ensino e pesquisa. São Paulo: Contexto, 2002. p. 221-231.

LACOSTE, Y. A Geografia - isso serve em primeiro lugar, para fazer a guerra. ed.4.Campinas: Papirus, 1997. 


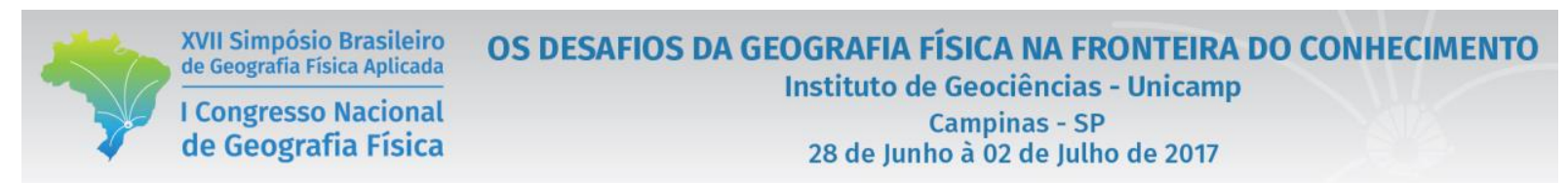

. Pesquisa e o trabalho de campo: um problema político para os pesquisadores, estudantes e cidadãos. São Paulo, AGB/SP, n. 11, 1-23, agosto de 1985.

NEVES, K. F. T. V. Os trabalhos de campo no ensino da geografia: reflexões sobre a prática docente na educação básica. Ilhéus: Editus, 2010.

OLIVEIRA, A. U. Para onde vai o ensino de geografia? São Paulo: Contexto, 2008.

PONTUSCHKA, N. N. Fundamentos para um projeto interdisciplinar: supletivo profissionalizante. In: PONTUSCHKA, N. N. e OLIVEIRA, A. U. (Org.). Geografia em Perspectiva: ensino e pesquisa. São Paulo: Contexto, 2002. p. 187-194.

ROSS, J. L. S. (org.). Geografia do Brasil. São Paulo: Editora Universidade de São Paulo, 2005.

SANTOS, M. Técnica, Espaço, Tempo: Globalização e meio técnico-científico. São Paulo: Hucitec, 1994. 